\title{
Movement disorders in metabolic disorders
}

José Luiz Pedroso ${ }^{1}, M D$, PhD; Orlando G. Barsottini ${ }^{1}, M D, P h D^{1}$; Alberto J. Espay ${ }^{2}$, $M D, M S c$;

1 - Division of General Neurology and Ataxia Unit, Department of Neurology, Universidade Federal de São Paulo, SP, Brazil;

2 - University of Cincinnati. Gardner Neuroscience Institute, Gardner Center for Parkinson's Disease and Movement Disorders, Cincinnati, OH, USA;

Correspondence to: Dr. Alberto J. Espay, Gardner Family Center for Parkinson's Disease and Movement Disorders, Department of Neurology, University of Cincinnati, Cincinnati, Ohio, USA Tel: +1 (513) 558-4035; e-mail: aespay@gmail.com

\section{Financial disclosure:}

Dr. Pedroso reports no disclosure

Dr. Barsottini reports no disclosure

Dr. Espay has received grant support from the NIH, Great Lakes Neurotechnologies and the Michael J Fox Foundation; personal compensation as a consultant/scientific advisory board member for Abbvie, TEVA, Impax, Acadia, Acorda, Cynapsus/Sunovion, Lundbeck, and USWorldMeds; publishing royalties from Lippincott Williams \& Wilkins, Cambridge University Press, and Springer; and honoraria from Abbvie, UCB, USWorldMeds, Lundbeck, Acadia, the American Academy of Neurology, and the Movement Disorders Society. 


\section{Page 2.}

Text word count: 1,952

Abstract word count: 108

Characters count of the title: 41

Number of figures: 2

Number of tables: 2

Number of videos: 1 (7 segments)

Number of references: 62 


\begin{abstract}
Purpose of review: We provide a review of the movement disorders that complicate selected metabolic disorders, including the abnormal movements that may appear during or after their treatment.
\end{abstract}

Recent findings: Movement disorders can accompany a broad range of medical conditions, including metabolic disorders.

Summary: The abnormal movements may occur as the initial manifestation of a systemic disease, at any time during its course, or as a result of the medical interventions required for its management. Not uncommonly the ascertainment of movement phenomenology may assist in the determination of the underlying metabolic disorder. The evaluation and treatment of movements disorders associated with metabolic disorders depends on the underlying pathophysiology.

Keywords: Movement disorders, abnormal movements, metabolic disorders, electrolytes, internal medicine. 


\section{Introduction}

Movement disorders such as parkinsonism, tremor, dystonia, chorea and myoclonus most often arise in several neurodegenerative or structural diseases of the basal ganglia [1]. They may also be part of the clinical manifestations of systemic metabolic disorders, as the initial feature, complicating its course, or as a result of the corrective treatment [2]. These metabolic disorders may also be associated with neurological manifestations that help the clinician suspect the nature of the problem,

such as disorders of consciousness, headache, and seizures [3]. The metabolic origin can also be suspected when movements abnormalities appear in emergency settings or in intensive care units [4].

Some common metabolic disorders, such as organ failure (particularly liver or renal insufficiency), endocrinological diseases (e.g., hyperglycemia) and electrolyte disturbances, frequently present with neurological dysfunction [5-7]. The pathophysiology of these movement disorders is complex and insufficiently understood [6]. Movement disorders may be the key abnormality, such as hemichorea in nonketotic hyperglycemia, or important component of a major syndrome, such as the myoclonus of renal insufficiency or the asterixis of hepatic encephalopathy [5-7]. Emphasizing the role of the neurologist, the clinical recognition of certain movements may serve to guide the proper diagnostic metabolic workup. Treatment of the abnormal movements in these cases usually relies on the correction of the underlying metabolic disorders. 
In this article, we comprehensively reviewed the most common metabolic disorders whose clinical spectrum include movement disorders and those arising in the context of the correction of the metabolic derangements. Abnormal movements associated with selected metabolic disorders are highlighted in Table 1.

\section{Endocrinological diseases}

\section{A. Thyroid diseases}

\section{Hypothyroidism}

Hypothyroidism and parkinsonism have many overlapping symptoms such as fatigue, depression, constipation, slowed movements and gait impairment. Thus, hypothyroidism is in the differential diagnosis for subtle parkinsonian features, particularly when associated with other signs such as brittle hair and temperature intolerance. Serum levels of thyroid hormones should always be requested in these cases. Of note, the use of levodopa may decrease TSH levels without affecting thyroid function [8]. In addition, Hashimoto's thyroiditis, as well as Hashimoto's encephalopathy, may present with chorea and myoclonus [9]. An encephalopathic state may not be necessary for chorea or myoclonus to arise in the context of Hashimoto's thyroiditis, and corticosteroid response may be absent. This has rendered inaccurate the term, "steroid-responsive encephalopathy associated with autoimmune thyroiditis" [10].

\section{Hyperthyroidism}


Hyperthyroidism may be associated with a range of movement disorders including chorea, ballism, athethosis, and dystonia, probably because thyroid hormones may affect the dopaminergic pathways [11]. Tremor is the most common movement disorder observed in hyperthyroidism, and it may occur in isolation or associated with systemic features, such as tachycardia and sweating [12]. This is a postural and action tremor, affecting the upper limbs. Rare presentations include cervical dystonia, ballism, myoclonus, ataxia and stiff-person syndrome $[10,11]$. In the latter, the endocrinopathy is autoimmune in nature, due to antibodies against glutamic acid decarboxylase (antiGAD) [13]. The presence of hyperthyroidism in Parkinson's disease and other parkinsonisms precludes tremor control until the thyroid disease is identified and treated $[12,14]$. Dystonia (writer's cramp) and chorea have been associated with Graves' disease $[11,15]$. Chorea induced by thyroid hormones replacement has also been occasionally described [16]. Symptoms tend to respond to beta-blockers and attenuate after correction of elevated thyroid levels.

\section{B. Parathyroid disease}

\section{Hypoparathyroidism}

Hypocalcemia related to idiopathic hypoparathyroidism may cause parkinsonism, dystonia, myoclonus, and chorea (Video - Segment 1) [17]. Rare cases of paroxysmal chorea may be kinesigenic [18]. An important clue to the presence of hypoparathyroidism is the presence of calcifications in the basal ganglia, whose pattern is similar to genetic causes of Fahr's syndrome [19] (Figure 1, A-C). 
Parkinsonism associated with hypoparathyroidism-related calcification of the basal ganglia usually does not respond to levodopa therapy, although some reports have suggested some therapeutic effect [20]. A pathophysiological mechanism may be direct dopaminergic dysfunction by hypoparathyroidism [17]. Parkinsonism may also occur as late complication after thyroidectomy [21].

In pseudohypoparathyroidism, PTH levels are normal, but a biological insensitivity to PTH occurs, which leads to hypocalcemia. In general, it may also be associated with parkinsonism and calcification of the basal ganglia but also to paroxysmal exercise-induced dystonia [22, 23].

\section{Hyperparathyroidism}

While the association of hyperparathyroidism with parkinsonism may be coincidental in some cases, parkinsonian features related to hyperparathyroidism may improve with correction of calcium and PTH levels or removal of parathyroid adenomas to a greater extent than dopaminergic medications [24]. Hyperparathyroidism may also worsen pre-existent parkinsonism [25].

\section{Metabolic and electrolyte disorders}

\section{A. Electrolyte disorders}

Electrolytic disorders and acid-base disturbances may present with several neurological symptoms, which may affect the central and peripheral nervous systems. 
Besides encephalopathy, electrolyte and acid-base disturbances may cause different subtypes of movement disorders [3].

Osmotic demyelination syndromes, which include pontine and extrapontine myelinolysis, may affect several areas of the central nervous system as a result of fast correction of hyponatremia, liver disease, prolonged parenteral nutrition, alcohol abuse, and malnutrition [26]. Myelinolysis, particularly extrapontine, with basal ganglia involvement, is usually comprised by parkinsonism, chorea, dystonia or myoclonus, along with neuropsychiatric symptoms [27-29]. The corresponding acute-onset parkinsonism may respond to levodopa, but most patients have residual deficits. Similarly, when the phenotype is chorea or athetosis, patients are often refractory to therapy [27]. This complication is suggested by neuroimaging demonstration of confluent areas of brainstem and basal ganglia T2-weighted and FLAIR hyperintensity (Figure 1, D-F).

Electrolyte disorders may present with a range of movement disorders (Table 1) [32]. Correction of the underlying electrolyte derangement reverses the associated neurological deficits. Disorders of potassium may not cause movement disorders but can induce severe weakness (technically, a loss of movement). Metabolic acidosis is suspected by the characteristic brain MRI abnormality in the basal ganglia: the fork sign

(Figure 2, A) [33].

\section{B. Glucose metabolism}

Chorea induced by non-ketotic hyperglycemia is associated with high serum glucose levels. After correction of the hyperglycemia the improvement may occur weeks or months later, but in some cases chorea may persist. The classic presentation is 
hemiballismus, which is a severe form of hemichorea (Video-Segment 3) [5, 34]. The corresponding brain MRI shows hyperintense signal in the striatum, which may also persist after the correction of the metabolic changes or even after the clinical recovery (Figure 2, B) [35]. The pathophysiology of this condition is not yet completely understood, but petechial microhemorrhage have been documented [36]. Also, hemichorea-hemiballismus may be associated with increased $\mathrm{GABA}_{\mathrm{B}}$ receptormediated activity in the motor cortex [37]. Although correction of glucose levels often suffices, some patients may require dopamine blocking agents (neuroleptics) for shortterm symptomatic control [5].

Chorea, myoclonus and paroxysmal dyskinesias have been rarely reported in hypoglycemia [38].

\section{Metabolic disorders associated with organ failure}

\section{A. Hepatic failure}

Acquired hepatolenticular degeneration refers to a syndrome with cognitive, motor, and psychiatric abnormalities related to liver insufficiency of any cause. Symptoms may occur insidiously or subacutely, within a few weeks or months. Involvement of the basal ganglia in acquired hepatocerebral degeneration may cause chorea, dystonia, tremor, parkinsonism and myoclonus [39, 40]. Orobuccolingual dyskinesias are frequently observed [41]. Most commonly, patients with hepatic encephalopathy present with asterixis, a form of negative postural myoclonus due to transient lapses in tone (Video - Segment 4). It is caused by portal-systemic shunting leading to excessive concentration of manganese in the globus pallidum [42]. The 
manganese deposition can be suspected by a hyperintense signal in the basal ganglia in T1-weighted brain MRI sequences (Figure 2, C). Improvement of the movement disorders related to hepatic failure requires treatment of hepatic encephalopathy, which may include liver transplantation, as appropriate [43]. It is imperative to distinguish acquired hepatocerebral degeneration from Wilson's disease, since both have similar phenotype, but different causes and treatments [44].

\section{B. Renal failure}

Neurological symptoms are frequent in patients with acute or chronic renal failure, including encephalopathy, seizures, and movement disorders $[6,45]$. Patients with chronic renal failure often develop only subtle neurological symptoms. Several movement disorders have been reported in patients with severe uremia and end-stage renal disease, particularly those with diabetic nephropathy. The most common are myoclonus, tremor and asterixis, usually associated to encephalopathy and seizures (Video - Segment 5). Chorea is rarely observed in uremia, mostly restricted to elderly patients $[6,46]$.

Uremia is capable of inducing secondary restless legs syndrome (RLS) and is frequently associated with neuropathy. The frequency of RLS in patients with renal failure is around 20 to $40 \%$, when compared to the general population. Pathophysiological mechanisms involved remain poorly understood but involve iron dysfunction and dopaminergic dysfunction. Dopaminergic replacement therapy, standard treatment for idiopathic RLS, can be futile in cases associated with renal failure or iron deficiency [47]. Correction of these abnormalities becomes necessary for symptomatic control. 
The association between myoclonus and renal failure may include an important differential diagnosis (Table 2). Hemodialysis patients may present with transient dysarthria and, occasionally, seizures. This results from transient osmotic imbalance during dialysis and is associated with hyperintense signal in the basal ganglia. Slower and longer sessions appear to prevent this phenomenon [48]. Patients with uremic encephalopathy consistently improve after dialysis or renal transplantation [5].

A very rare autosomal recessive disease called action myoclonus-renal failure syndrome is caused by a loss-of-function mutation of the SCARB2 gene [49]. Myoclonus persists after renal transplantation in these patients.

\section{Cardiac arrest and brain hypoxia}

Anoxia after cardiac arrest or related to insufficient cerebral blood flow (Eg. septic shock) induces a global brain injury, presenting as diffuse encephalopathy. Pathophysiological mechanisms involve not only neuronal and glial damage, but also excitatory brain injury. A glutamate efflux increases intracellular calcium and cytokines that lead to proinflammatory states. The most susceptible brain regions affected in anoxia are hippocampus, basal ganglia, Purkinje cells, and neocortex [50].

Several movement disorders may occur after cardiac arrest, related to hypoxic or anoxic complications. Although myoclonus is the most common, patients may also present chorea, parkinsonism, tremor, dystonia and tics (Video-Segment 6) [51]. Patients with myoclonus after cardiac arrest must undergo electroencephalogram to evaluate for focal myoclonic seizures, which would require selected antiepileptic drugs, sodium valproate, levetiracetam and/or clonazepam [52, 53]. 
Lance-Adams syndrome is characterized by chronic myoclonus, ataxia and cognitive impairment that appear days or weeks after cardiac arrest and disabling action myoclonus is common [54]. These patients tend have had preexistent hypercapnia due to respiratory failure (from severe pneumonia or asthma, for instance), which explains this complication is uncommon after cardiac arrest not preceded by respiratory insufficiency, even if it has been rarely reported after "brief hypoxemia" (e.g., after a surgery or anesthesia) without cardiac arrest [55].

Post-pump chorea usually occurs after cardiopulmonary bypass or after congenital heart surgery in children (Video - Segment 7). Orofacial dyskinesias, hypotonia, ballismus and supranuclear gaze palsy may be present in these patients [56, 57].

\section{Miscellaneous disorders}

\section{Polycythemia}

Polycythemia rubra vera is a myeloproliferative disease characterized by increased red blood cells. Neurological manifestations may include headache, vertigo, paresthesias, visual deficits, ischemic stroke or tinnitus. Rarely, polycythemia rubra vera may present with movement disorders, most commonly chorea [58]. Chorea restricted to the orofaciolingual region or to a hemibody (hemichorea) may also be part of the phenotypic spectrum $[58,59]$. Chorea has also been reported associated with secondary causes of polycythemia [60]. 
Iron dysregulation

Several neurodegenerative diseases, such as neurodegeneration with brain iron accumulation (NBIA) and Friedreich ataxia, are associated with dysregulation of brain iron metabolism [61]. Hemochromatosis, a genetic disease, may increase iron content in basal ganglia but is unlikely to cause movement disorders [62].

\section{Conclusions}

Abnormal movements associated with metabolic disorders are common in daily clinical practice. Because of the therapeutic implications, general neurologists, clinicians and hospitalists must be aware about the subtypes of movement disorders and the most common metabolic conditions associated with these neurological manifestations. Movement disorders may be the most prominent neurological symptoms in metabolic abnormalities. Treatment of the underlying metabolic disorders usually improve the associated abnormal movements. 


\section{References}

1. Stoessl AJ, Mckeown MJ. Movement disorders. Handb Clin Neurol. 2016;136:957-69.

2. Poewe W, Djamshidian-Tehrani A. Movement disorders in systemic diseases. Neurol Clin. 2015;33(1):269-97.

* Movement disorders may be the initial manifestation of a systemic disease. In this review the authors discuss the most common movement disorders which may present in infectious, autoimmune, paraneoplastic, and also in metabolic and endocrine diseases.

3. Riggs JE. Neurologic manifestations of electrolyte disturbances. Neurol Clin. 2002;20(1):227-39.

4. Dallocchio C, Matinella A, Arbasino C, Arno' N, Glorioso M, Sciarretta M, et al. Movement disorders in emergency settings: a prospective study. Neurol Sci. 2018 Oct 15 [Epub ahead of print].

5. Chen C, Zheng H, Yang L, Hu Z. Chorea-ballism associated with ketotic hyperglycemia. Neurol Sci. 2014;35(12):1851-5.

6. Seifter JL, Samuels MA. Uremic encephalopathy and other brain disorders associated with renal failure. Semin Neurol. 2011;31(2):139-43.

7. Ellul MA, Cross TJ, Larner AJ. Asterixis. Pract Neurol. 2017;17(1):60-2.

8. Munhoz RP, Teive HA, Troiano AR, Hauck PR, Herdoiza Leiva MH. Parkinson's disease and thyroid dysfunction. Parkinsonism Relat Disord. $2004 ; 10(6): 381-3$.

9. Baizabal-Carvallo JF, Jankovic J. Movement disorders in autoimmune diseases. Mov Disord. 2012;27(8):935-46. 
10. Miranda M, Bustamante ML, Campero M, Wainstein E, Toche P, Espay AJ, et al. Movement disorders in non-encephalopathic Hashimoto's thyroiditis. Parkinsonism Relat Disord. 2018;55:141-2.

11. Tan EK, Chan LL. Movement disorders associated with hyperthyroidism: Expanding the phenotype. Mov Disord. 2006;21(7):1054-15.

12. Tan EK, Lo YL, Chan LL. Graves disease and isolated orthostatic tremor. Neurology. 2008;70(16 Pt 2):1497-8.

13. Orija IB, Gupta M, Zimmerman RS. Graves' disease and stiff-person (stiffman) syndrome: case report and literature review. Endocr Pract. 2005;11(4):25964.

14. Kim HT, Edwards MJ, Lakshmi Narsimhan R, Bhatia KP. Hyperthyroidism exaggerating parkinsonian tremor: a clinical lesson. Parkinsonism Relat Disord. 2005;11(5):331-2.

15. Yu JH, Weng YM. Acute chorea as a presentation of Graves disease: case report and review. Am J Emerg Med. 2009;27(3):369.e1-3.

16. Kondziella D, Brederlau A, Asztely F. Choreathetosis due to abuse of levothyroxine. J Neurol. 2009;256(12):2106-8.

17. Gálvez-Jiménez N, Hanson MR, Cabral J. Dopa-resistant parkinsonism, oculomotor disturbances, chorea, mirror movements, dyspraxia, and dementia: the expanding clinical spectrum of hypoparathyroidism. A case report. Mov Disord. 2000;15(6):1273-6.

18. Micheli F, Pardal MF, Parera IC, Giannaula R. Idiopathic hypoparathyroidism and paroxysmal kinesigenic choreoathetosis. Ann Neurol. 1989;26(3):415.

19. Quintáns B, Oliveira J, Sobrido MJ. Primary familial brain calcifications. Handb Clin Neurol. 2018;147:307-17. 
20. Vaamonde J, Legarda I, Jimenez-Jimenez J, Zubieta JL, Obeso JA. Levodoparesponsive parkinsonism associated with basal ganglia calcification and primary hypoparathyroidism. Mov Disord. 1993;8(3):398-400.

21. Uncini A, Tartaro A, Di Stefano E, Gambi D. Parkinsonism, basal ganglia calcification and epilepsy as late complications of postoperative hypoparathyroidism. J Neurol. 1985;232(2):109-11.

22. Song CY, Zhao ZX, Li W, Sun CC, Liu YM. Pseudohypoparathyroidism with basal ganglia calcification: A case report of rare cause of reversible parkinsonism. Medicine (Baltimore). 2017;96(11):e6312.

23. Dure LS 4th, Mussell HG. Paroxysmal dyskinesia in a patient with pseudohypoparathyroidism. Mov Disord. 1998;13(4):746-8.

24. De Rosa A, Rinaldi C, Tucci T, Pappatà S, Rossi F, Morra VB, et al. Coexistence of primary hyperparathyroidism and Parkinson's disease in three patients: an incidental finding? Parkinsonism Relat Disord. 2011;17(10):771-3.

25. Ohya Y, Osaki M, Sakai S, Kimura S, Yasuda C, Ago T, et al. A case of hyperparathyroidism-associated parkinsonism successfully treated with cinacalcet hydrochloride, a calcimimetic. BMC Neurol. 2018;18(1):62.

26. Singh TD, Fugate JE, Rabinstein AA. Central pontine and extrapontine myelinolysis: a systematic review. Eur J Neurol. 2014;21(12):1443-50.

27. Tan AH, Lim SY, Ng RX. Osmotic Demyelination Syndrome With Evolving Movement Disorders. JAMA Neurol. 2018;75(7):888-9.

28. de Souza A. Movement disorders and the osmotic demyelination syndrome. Parkinsonism Relat Disord. 2013;19(8):709-16. 
29. Seah ABH, Chan LL, Wong MC, Tan EK. Evolving spectrum of movement disorders in extrapontine and central pontine myelinolysis. Parkinsonism Relat Disord. 2002;9(2):117-9.

30. Shibasaki H. Pathophysiology of negative myoclonus and asterixis. In: Fahn S, Hallett M, Luders HO, Marsden CD, editors. Negative Motor Phenomena, Adv. Neurol., vol. 67. Philadelphia: Lippincott-Raven Publishers; 1995. p. 199-207.

31. Rubboli G, Tassinari CA. Negative myoclonus. An overview of its clinical features, pathophysiological mechanisms, and management. Neurophysiol Clin. 2006;36(5-6):337-43.

32. Espay AJ. Neurologic complications of electrolyte disturbances and acid-base balance. Handbook of Clinical Neurology, Vol. 119 (3rd series) Neurologic Aspects of Systemic Disease Part I Jose Biller and Jose M. Ferro, Editors (C) 2014 Elsevier B.V.

33. Grasso D, Borreggine C, Perfetto F, Bertozzi V, Trivisano M, Specchio LM, et al. Lentiform fork sign: a magnetic resonance finding in a case of acute metabolic acidosis. Neuroradiol J. 2014;27(3):288-92.

34. Lin JJ, Chang MK. Hemiballism-hemichorea and non-ketotic hyperglycaemia. J Neurol Neurosurg Psychiatry. 1994;57(6):748-50.

35. Duker AP, Espay AJ. Images in clinical medicine. Hemichorea-hemiballism after diabetic ketoacidosis. N Engl J Med. 2010;363(17):e27.

36. Li JY, Chen R. Increased intracortical inhibition in hyperglycemic hemichoreahemiballism. Mov Disord. 2015;30(2):198-205.

37. Atay M, Yetis H, Kurtcan S, Aralasmak A, Alkan A. Susceptibility weighted imaging features of nonketotic hyperglycemia: unusual cause of hemichoreahemiballismus. J Neuroimaging. 2015;25(2):319-24. 
38. Wolz M, Reichmann H, Reuner U, Storch A, Gerber J. Hypoglycemia-induced choreoathetosis associated with hyperintense basal ganglia lesions in T1weighted brain MRI. Mov Disord. 2010;25(7):966-8.

39. Renjen PN, Khanna L, Rastogi R, Khan NI. Acquired hepatocerebral degeneration. BMJ Case Rep. 2013;Jun 18:2013.

40. Ferrara J, Jankovic J. Acquired hepatocerebral degeneration. J Neurol. 2009;256(3):320-32.

41. Thobois S, Giraud P, Debat P, Gouttard M, Maurizi A, Perret-Liaudet A, et al. Orofacial dyskinesias in a patient with primary biliary cirrhosis: a clinicopathological case report and review. Mov Disord. 2002;17(2):415-9.

42. Klos KJ, Ahlskog JE, Josephs KA, Fealey RD, Cowl CT, Kumar N. Neurologic spectrum of chronic liver failure and basal ganglia T1 hyperintensity on magnetic resonance imaging: probable manganese neurotoxicity. Arch Neurol. 2005;62(9):1385-90.

43. Stracciari A, Guarino M, Pazzaglia P, Marchesini G, Pisi P. Acquired hepatocerebral degeneration: full recovery after liver transplantation. J Neurol Neurosurg Psychiatry 2001;70(1):136-7.

44. Fernández-Rodriguez R, Contreras A, De Villoria JG, Grandas F. Acquired hepatocerebral degeneration: clinical characteristics and MRI findings. Eur J Neurol. 2010;17(12):1463-70.

45. Lee PH, Shin DH, Kim JW, Song YS, Kim HS. Parkinsonism with basal ganglia lesions in a patient with uremia: evidence of vasogenic edema. Parkinsonism Relat Disord. 2006;12(2):93-6. 
46. Badhwar A, Berkovic SF, Dowling JP, Gonzales M, Narayanan S, Brodtmann A, et al. Action myoclonus-renal failure syndrome: characterization of a unique cerebro-renal disorder. Brain. 2004;127(Pt 10):2173-82.

47. Janzen L, Rich JA, Vercaigne LM. An overview of levodopa in the management of restless legs syndrome in a dialysis population: pharmacokinetics, clinical trials, and complications of therapy. Ann Pharmacother. 1999;33(1):86-92.

48. Finelli PF, Singh JU. A syndrome of bilateral symmetrical basal ganglia lesions in diabetic dialysis patients. Am J Kidney Dis. 2014;63(2):286-8.

49. Berkovic SF, Dibbens LM, Oshlack A, Silver JD, Katerelos M, Vears DF, et al. Array-based gene discovery with three unrelated subjects shows SCARB2/LIMP-2 deficiency causes myoclonus epilepsy and glomerulosclerosis. Am J Hum Genet. 2008;82(3):673-84.

50. Fugate JE. Anoxic-Ischemic Brain Injury. Neurol Clin. 2017;35(4):601-11.

51. Venkatesan A, Frucht S. Movement disorders after resuscitation from cardiac arrest. Neurol Clin. 2006;24(1):123-32.

52. Wijdicks EF, Parisi JE, Sharbrough FW. Prognostic value of myoclonus status in comatose survivors of cardiac arrest. Ann Neurol. 1994;35(2):239-43.

53. Aicua Rapun I, Novy J, Solari D, Oddo M, Rossetti AO. Early Lance-Adams syndrome after cardiac arrest: Prevalence, time to return to awareness, and outcome in a large cohort. Resuscitation. 2017;115:169-72.

54. Lance JW, Adams RD. The syndrome of intention or action myoclonus as a sequel to hypoxic encephalopathy. Brain. 1963;86:111-36.

55. Cho AR, Kwon JY, Kim JY, Kim ES, Kim HY. Acute onset LanceAdams syndrome following brief exposure to severe hypoxia without cardiac arrest -a case report-. Korean J Anesthesiol. 2013;65(4):341-4. 
56. Kirkham FJ, Haywood P, Kashyape P, Borbone J, Lording A, Pryde K, et al. Movement disorder emergencies in childhood. Eur J Paediatr Neurol. 2011;15(5):390-404.

57. Bisciglia M, London F, Hulin J, Peeters A, Ivanoiu A, Jeanjean A. Choreoathetotic syndrome following cardiac surgery. J Clin Anesth. 2017;36:59-61.

58. Bruyn GW, Padberg G. Chorea and polycythaemia. Eur Neurol. 1984;23(1):2633.

59. Midi I, Dib H, Köseoglu M, Afsar N, Günal DI. Hemichorea associated with polycythaemia vera. Neurol Sci. 2006;27(6):439-41.

60. Edwards PD, Prosser R, Wells CE. Chorea, polycythaemia, and cyanotic heart disease. J Neurol Neurosurg Psychiatry. 1975;38(8):729-39.

61. Dusek P, Jankovic J, Le W. Iron dysregulation in movement disorders. Neurobiol Dis. 2012;46(1):1-18.

62. Russo N, Edwards M, Andrews T, O'Brien M, Bhatia KP. Hereditary haemochromatosis is unlikely to cause movement disorders--a critical review. J Neurol. 2004;251(7):849-52. 


\section{Figure legends}

Figure 1. Brain CT scan in primary hypoparathyroidism. Note diffuse bilateral calcification in the basal ganglia, thalamus (A and B) and dentate nucleus (C) calcification. Courtesy of Dr. Miryam Carecchio, Department of Neuroscience, University of Padua, Padua, Italy. Brain MRI in extrapontine myelinolysis. This complication was brought on by fast correction of hyponatremia, presenting with reduced level of consciousness and parkinsonism. Axial FLAIR-weighted (D and E) and T2-weighted (F) sequencing shows symmetrical hyperintense signal in basal ganglia and thalamus.

Figure 2. Brain MRI in metabolic acidosis. Axial FLAIR brain MRI shows bilateral symmetrical hyperintense signal in the basal ganglia that delineate the lentiform nucleus (fork sign) (A). Neuroimaging in non-ketotic hyperglycemia in a patient with rightsided hemichorea/hemiballismus. Axial T1-weighted brain MRI revealed hyperintense signal in the same region (B). Courtesy of Dr. Victor Hugo Rocha Marussi, Department of Radiology, Hospital Beneficência Portuguesa, SP, Brazil. Brain MRI in acquired hepatolenticular degeneration. Axial T1-weighted brain MRI shows symmetrical hyperintense signal in basal ganglia, suggestive of manganese deposition (C).

\section{Table legends}

Table 1: Movement disorders and selected examination signs in metabolic disorders.

Table 2: Differential diagnosis when myoclonus and renal failure coexist. 


\section{Video Legend}

Video: We illustrate with 6 patients selected movement disorders associated with metabolic disorders. Segment 1: chorea in the setting of primary hypoparathyroidism with basal ganglia calcification (Courtesy of Dr. Thiago Cardoso Vale, from the Department of Neurology, Federal University of Juiz de For a, MG, Brazil). Segment 2: Trousseau sign in hypomagnesemia. Segment 3: hemichorea-hemiballism due to nonketotic hyperglycemia. Segment 4: asterixis in hepatic failure (Courtesy of Dr.

Guilherme Felga, from the Albert Einstein Hospital, SP, Brazil). Segment 5: tremor and myoclonus in uremic encephalopathy/renal failure. Segment 6: myoclonus in postcardiac arrest anoxic encephalopathy. Segment 7: post-pump chorea after cardiac valve replacement surgery.

Table 1. Movement disorders and selected examination signs in metabolic disorders

\begin{tabular}{|c|c|c|c|}
\hline & \multicolumn{3}{|c|}{ Metabolic disorders } \\
\hline $\begin{array}{l}\text { Movement } \\
\text { disorders }\end{array}$ & Common & Uncommon, but typical & Uncommon \\
\hline Parkinsonism & & $\begin{array}{l}\text { Hypoparathyroidism } \\
\text { (with basal ganglia } \\
\text { calcification) }\end{array}$ & $\begin{array}{l}\text { Hypothyroidism } \\
\text { Hepatic failure } \\
\text { Hyperparathyroidism } \\
\text { Renal failure }\end{array}$ \\
\hline Chorea & & Polycythemia & $\begin{array}{l}\text { Anoxic encephalopathy } \\
\text { Hyperthyroidism } \\
\text { Hypoglycemia } \\
\text { Hypoparathyroidism } \\
\text { Hepatic failure } \\
\text { Renal failure } \\
\text { Hypernatremia } \\
\text { Hypomagnesemia }\end{array}$ \\
\hline $\begin{array}{l}\text { Hemichorea / } \\
\text { hemiballism }\end{array}$ & & Hyperglycemia & Polycythemia \\
\hline Myoclonus & $\begin{array}{l}\text { Hepatic failure } \\
\text { Renal failure } \\
\text { Hypernatremia } \\
\text { Anoxic encephalopathy }\end{array}$ & & $\begin{array}{l}\text { Hypoparathyroidism } \\
\text { Hypoglycemia } \\
\text { Hypercalcemia } \\
\text { Alkalosis } \\
\text { Hyponatremia }\end{array}$ \\
\hline
\end{tabular}




\begin{tabular}{|c|c|c|c|}
\hline & & & Hypomagnesemia \\
\hline Tremor & $\begin{array}{l}\text { Hyperthyroidism, } \\
\text { Hepatic failure } \\
\text { Hypernatremia }\end{array}$ & & $\begin{array}{l}\text { Anoxic encephalopathy } \\
\text { Alkalosis } \\
\text { Hypomagnesemia }\end{array}$ \\
\hline Dystonia & & & $\begin{array}{l}\text { Hyperthyroidism } \\
\text { Hepatic failure } \\
\text { Hypoparathyroidism } \\
\text { Anoxic encephalopathy }\end{array}$ \\
\hline Ballism & & & Hyperthyroidism \\
\hline Asterixis & $\begin{array}{l}\text { Hepatic failure } \\
\text { Renal failure }\end{array}$ & & Acidosis \\
\hline Ataxia & & & $\begin{array}{l}\text { Renal failure } \\
\text { Hepatic failure }\end{array}$ \\
\hline $\begin{array}{l}\text { Paroxysmal } \\
\text { dyskinesias }\end{array}$ & & & Hypoglycemia \\
\hline $\begin{array}{l}\text { Orofacial } \\
\text { dyskinesias }\end{array}$ & & Hepatic failure & Polycythemia (vera) \\
\hline $\begin{array}{l}\text { Restless legs } \\
\text { syndrome }\end{array}$ & $\begin{array}{l}\text { Chronic renal failure } \\
\text { Iron deficiency }\end{array}$ & & \\
\hline Tics & & & Anoxic encephalopathy \\
\hline Tetany & Hypocalcemia & & $\begin{array}{l}\text { Hypomagnesemia } \\
\text { Alkalosis }\end{array}$ \\
\hline $\begin{array}{l}\text { Trousseau's sign } \\
\text { (Video - } \\
\text { Segment 2) }\end{array}$ & $\begin{array}{l}\text { Hypocalcemia } \\
\text { Hypomagnesemia }\end{array}$ & & \\
\hline
\end{tabular}

Table 2. Differential diagnosis when myoclonus and renal failure coexist.

\begin{tabular}{|l|l|l|l|}
\hline & Cause & Symptoms & Treatment \\
\hline $\begin{array}{l}\text { Uremic } \\
\text { encephalopathy }\end{array}$ & Renal failure & myoclonus & Dialysis or renal transplantation \\
\hline $\begin{array}{l}\text { Dialysis } \\
\text { encephalopathy }\end{array}$ & $\begin{array}{l}\text { Aluminium toxicity, } \\
\text { rapid uremia reduction }\end{array}$ & $\begin{array}{l}\text { Myoclonus, speech } \\
\text { disturbance, and seizures }\end{array}$ & $\begin{array}{l}\text { Avoid aluminum-containing dialytic } \\
\text { fluids, slow correction of uremia }\end{array}$ \\
\hline $\begin{array}{l}\text { Drug toxicity } \\
\text { (iatrogenic) }\end{array}$ & $\begin{array}{l}\text { Myoclonus-inducing } \\
\text { drugs in renal failure* }\end{array}$ & Myoclonic encephalopathy & $\begin{array}{l}\text { Avoid acyclovir, ciprofloxacine, } \\
\text { dobutamine, cephalosporins, and } \\
\text { gabapentin in uremic patients }\end{array}$ \\
\hline $\begin{array}{l}\text { Action myoclonus- } \\
\text { renal failure } \\
\text { syndrome }\end{array}$ & $\begin{array}{l}\text { SCRBA2 mutations } \\
\text { (autosomal recessive) }\end{array}$ & $\begin{array}{l}\text { Myoclonus without } \\
\text { encephalopathy; proteinuric } \\
\text { glomerulonephropathy }\end{array}$ & $\begin{array}{l}\text { First line: Levetiracetam, Topiramate, } \\
\text { Zonisamide; Second line: clonazepam }\end{array}$ \\
\hline
\end{tabular}

* Myoclonus-inducing drugs in renal disease include acyclovir, ciprofloxacine, dobutamine, cephalosporins, and gabapentin 
Figure 1
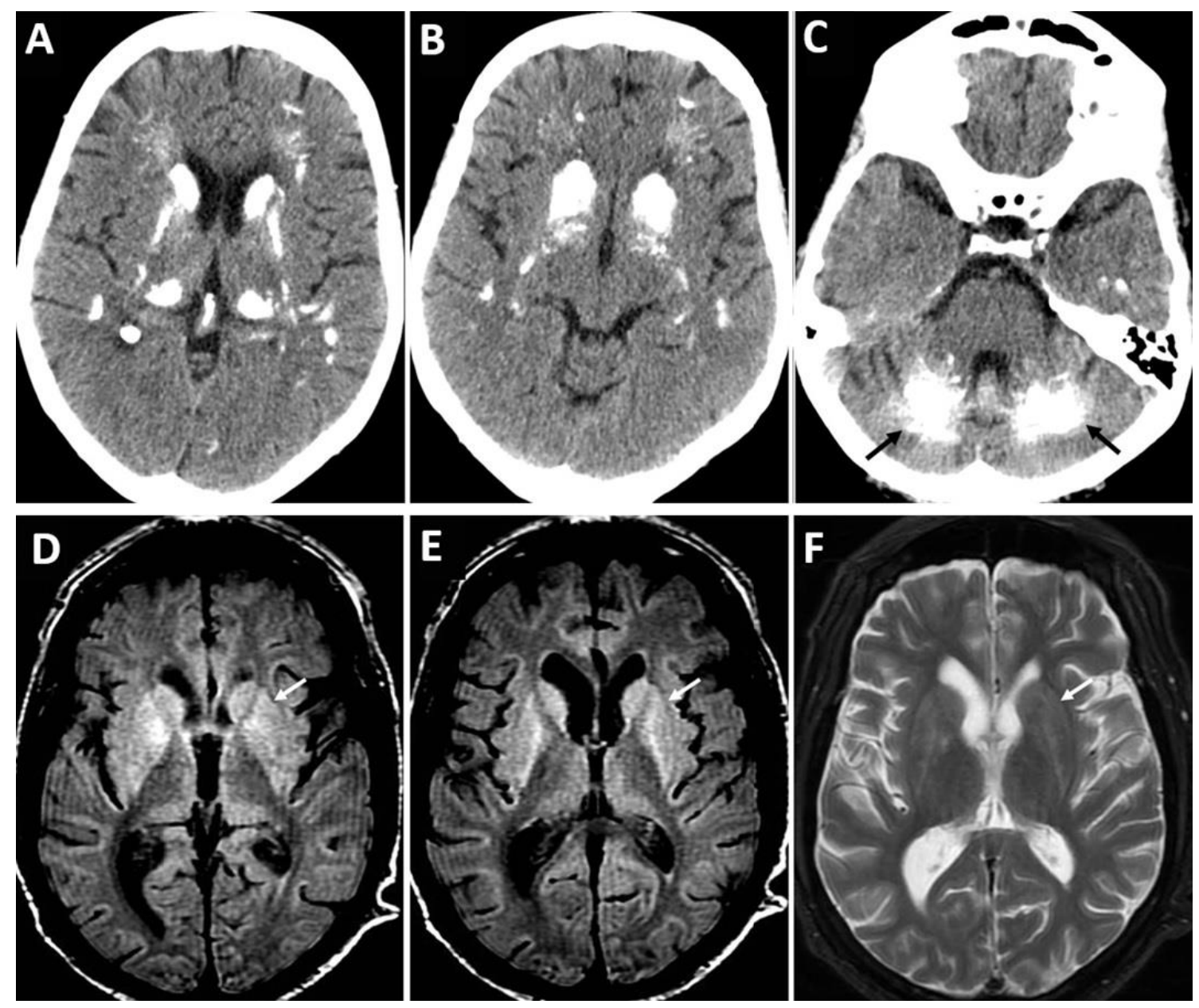

Figure 2
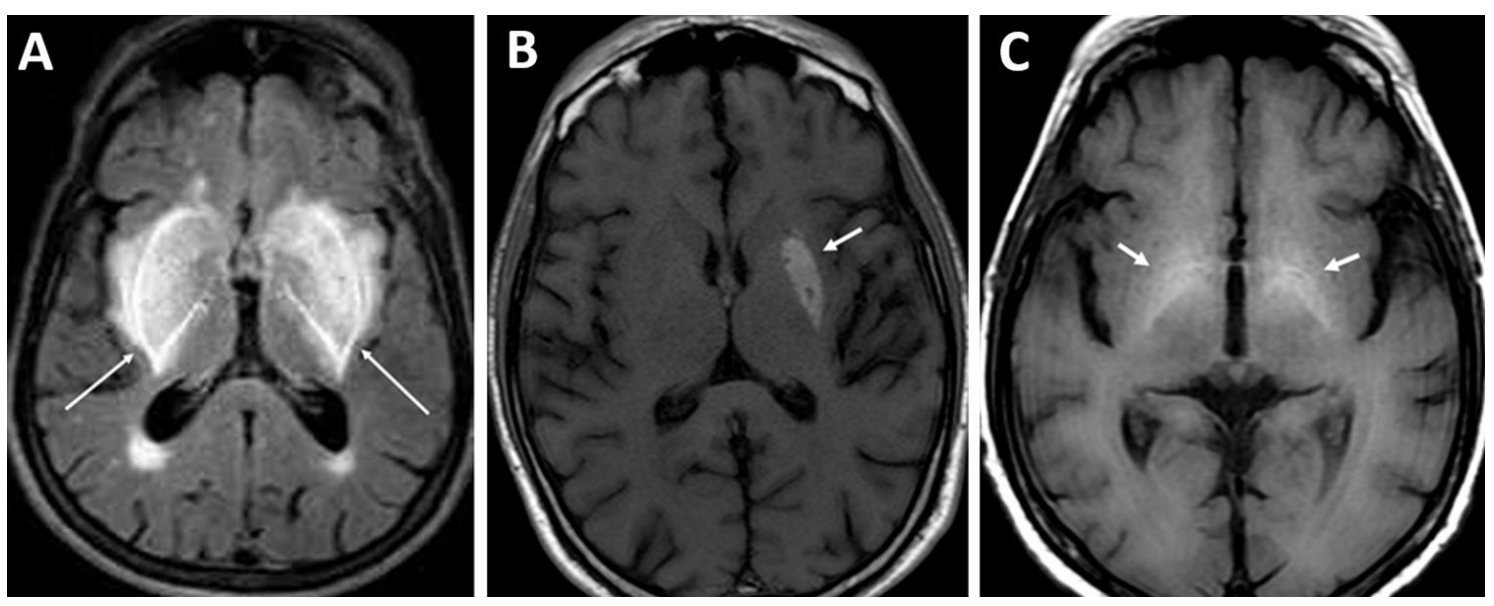